\title{
Postura e comportamento lactacional de matrizes suínas mantidas sob condições de temperatura ambiente elevada
}

\author{
Terezinha Domiciano Dantas Martins ${ }^{1 *}$ \\ Alberto Neves Costa ${ }^{2}$ \\ José Humberto Vilar da Silva ${ }^{1}$ \\ Rômulo Menna Barreto Valença ${ }^{3}$ \\ Jorge Vitor Ludke ${ }^{4}$ \\ ${ }^{1}$ Departamento de Agropecuária, Universidade Federal da Paraíba, Campus III \\ CEP 58220-000, Bananeiras - PB, Brasil \\ ${ }^{2} \mathrm{CNPq}-\mathrm{FAPERN}$, Departamento de Agropecuária \\ Universidade Federal do Rio Grande do Norte, Natal - RN, Brasil \\ ${ }^{3}$ Clínica Escola Veterinária FEJAL-CESMAC, Marechal Deodoro - AL, Brasil \\ ${ }^{4}$ Embrapa Suínos e Aves, Concórdia - SC, Brasil \\ *Autor para correspondência \\ domidantas@yahoo.com.br
}

Submetido em 12/02/2008

Aceito para publicação em 20/06/2008

\section{Resumo}

O comportamento de matrizes suínas lactantes mantidas em ambiente quente foi determinado em 23 fêmeas de $1^{\mathrm{a}}, 2^{\mathrm{a}}, 3^{\mathrm{a}} \mathrm{e} \geq 4^{\mathrm{a}}$ ordem de parição (OP), avaliadas em quatro períodos do dia - 06 às $12 \mathrm{~h}(\mathrm{P} 1) ; 12$ às $18 \mathrm{~h}(\mathrm{P} 2) ; 18$ às $24 \mathrm{~h}(\mathrm{P} 3), 24$ às $06 \mathrm{~h}(\mathrm{P} 4)$. Foram detectadas a freqüência $\left(\mathrm{n}^{\circ}\right)$ e a duração (min) em que as matrizes ficavam sentadas (SE), em decúbito lateral (DL) e decúbito ventral (DV), em pé em ócio (OEP), ou em pé em atividade no comedouro ou bebedouro (PACB). Quanto ao comportamento lactacional foi avaliada a freqüência, o tipo e a duração da amamentação terminada pela porca (ATPOR) ou pelos leitões (ATLEI) ou concluída com sucesso (ACS). A OP influenciou o tempo usado em DL e em PACB. Com exceção da OEP, houve efeito $(\mathrm{P}<0,05)$ do período do dia para as demais variáveis. Conclui-se que matrizes suínas ficaram inquietas e reduziram a freqüência da postura em decúbito lateral e o número de amamentações terminadas pelos leitões nos períodos mais quentes do dia.

Unitermos: estresse térmico, comportamento, porças, lactação

\section{Abstract}

Posture and behavior of sows in lactating maintained under conditions of high environmental temperature. The behavior of twenty-three hybrid lactating sows from the $1^{\text {st }}, 2^{\text {nd }}, 3^{\text {rd }}$ and $4^{\text {th }}$ parity orders maintained in a warm environment was evaluated during the four periods of Day 17 of lactation (6 to 12 a.m. (P1), 12 a.m. to 6 p.m. (P2), 6 p.m. to 12 p.m. (P3), and 12 p.m. to 6 a.m. (P4)). The frequency (n) and duration $(\mathrm{min})$ in which the sows remained lying down (SE), in lateral (DL) or ventral (DV) decubitus, standing up, but idle (OEP) or in activity at the feeder or drinker (PACB) was detected. Evaluations in relation to behavior during lactation included the frequency, type and duration of sucking terminated by the sow (ATPOR), terminated by 
the piglets (ATLEI) or successfully concluded. Parity order (OP) influenced the time used in DL and in PACB. There was a significant effect $(\mathrm{P}<0.05)$ of the period of the day for all variables except $\mathrm{OEP}$. In connection with this, it can be concluded that all sows became more restless during the warmest periods of the day, reducing the frequency of posture in DL and the number of suckings by the piglets.

Key words: thermal stress, behavior, swine, lactation

\section{Introdução}

O comportamento materno das fêmeas suínas é caracterizado por interações sincronizadas, entre as matrizes e suas leitegadas. Uma amamentação típica realiza-se em intervalos regulares de 45 a $50 \mathrm{~min}$, e inicialmente envolve vocalizações sucessivas emitidas pela matriz e uma prévia massagem das tetas pelos leitões. Em seguida, ocorre um breve período de ejeção do leite e uma massagem das tetas pós-ejeção (Algers, 1993). Entretanto, esta conduta padrão pode ser modificada, em resposta a vários fatores, entre os quais a ordem de parição (Thodberg et al., 2002) e temperatura ambiente elevada (Renaudeau et al., 2003a).

O estresse calórico em matrizes suínas lactantes provoca alterações no comportamento ingestivo, sendo percebida redução no consumo de alimentos, no tamanho da refeição diária e no tempo de ingestão (Quiniou et al., 2000a; Renaudeau et al., 2003c). Concomitantemente, reduzem o pico de consumo e aumentam a ingestão de alimentos à noite ou nas horas mais frias do dia (Gourdine et al., 2006).

Os efeitos do estresse calórico também incluem mudanças na postura e na conduta materna e, juntamente com as alterações no comportamento ingestivo, foram responsáveis pelo baixo desempenho produtivo das matrizes e de suas leitegadas (Quiniou e Noblet, 1999; Renaudeau e Noblet, 2001; Renaudeau et al., 2003b). Porém, quando a exposição ao calor foi por um período de tempo mais longo, estas respostas parecem menos intensas, sugerindo uma possível adaptação fisiológica dos animais (Spencer et al., 2003).

Resultados de pesquisas desenvolvidas por Gourdine et al. (2006) indicaram que o consumo alimentar e o comportamento ingestivo de matrizes lactantes também podem ter influência da genética utilizada, sendo as fêmeas Large White mais tolerante ao calor do que as crioulas. Entretanto, estas relações precisam ser investigadas em matrizes suínas provenientes de genéticas desenvolvidas em ambientes de clima temperado e criadas em regiões de clima tropical ou sub-tropical, onde prevalecem temperaturas ambientais elevadas constantes.

O objetivo deste estudo foi caracterizar a postura e o comportamento da amamentação de matrizes suínas híbridas, criadas sob condições de temperatura ambiente elevada na Zona da Mata de Pernambuco, como forma de gerar informações sobre o comportamento adaptativo destes animais.

\section{Material e Métodos}

O experimento foi conduzido durante os meses de verão (janeiro a março), numa granja comercial de suínos, localizada no Nordeste brasileiro, especificamente no município de Paudalho que está situado na Zona da Mata Setentrional de Pernambuco, a $7^{\circ} 55^{\prime} 58,3^{\prime}$ 'de LS e $35^{\circ} 8^{\prime} 12,8^{\prime \prime}$ de LO, com altitude de $70 \mathrm{~m}$, apresentando clima quente e úmido (Fundação de Desenvolvimento Municipal do Interior de Pernambuco, 1994). O clima predominante da região, de acordo com Köppen é As'tropical chuvoso (quente e úmido) com verão seco.

Foram utilizadas 23 fêmeas suínas híbridas lactantes, linhagem Dalland (C40) no $17^{\circ}$ dia de lactação $\left(16^{\circ}\right.$ a $\left.19^{\circ}\right)$, distribuídas aleatoriamente de acordo com a ordem de parição $\left(1^{\mathrm{a}}, 2^{\mathrm{a}}, 3^{\mathrm{a}} \mathrm{e} \geq 4^{\mathrm{a}}\right)$ e avaliadas em quatro períodos equivalentes do dia: período $1(\mathrm{P} 1)=$ de 06 às $12 \mathrm{~h} ; \mathrm{P} 2=12$ às $18 \mathrm{~h}$; de $\mathrm{P} 3=$ de 18 às $24 \mathrm{~h}$, e $\mathrm{P} 4=$ de 24 às $06 \mathrm{~h}$.

Foram usadas instalações de maternidade construídas no sentido Leste-Oeste, sem lanternin, laterais abertas com muretas de $0,75 \mathrm{~cm}$, beirais longos $(1,40 \mathrm{~m})$, e com cobertura de telhas de fibro-cimento pintadas externamente com tinta refletiva. O galpão possuía cortinas de polietileno com dispositivos de controle de abertura lateral, com movimentos de baixo para cima e vice-versa, sendo geralmente 
abertas às $7 \mathrm{~h} 30 \mathrm{~min}$ e fechadas em torno de $18 \mathrm{~h}$. Os seis ventiladores de 1730rpm (modelo NBR - 7094), localizados internamente nas laterais da sala a uma altura de $2 \mathrm{~m}$ do piso, eram acionados, rotineiramente, das 11 até às $16 \mathrm{~h}$.

As gaiolas eram equipadas com comedouro convencional (alvenaria) e bebedouro do tipo vaso comunicantes para as matrizes, bem como, abrigos escamoteadores e bebedouros, tipo concha e chupeta para os leitões.

As variáveis ambientais foram monitoradas através de termômetros de bulbo seco/úmido e de globo negro (Tg) instalados a uma altura de $1,00 \mathrm{~m}$ do piso, na lateral interna e no centro da sala de maternidade, respectivamente, correspondente à altura média do dorso dos animais. As leituras foram realizadas em intervalos de duas horas, a partir de 8 até às $18 \mathrm{~h}$, sendo os valores obtidos usados para calcular o índice de temperatura de globo negro e umidade (ITGU) de acordo com Buffington et al. (1981). Diariamente, foram registrados os valores das temperaturas máximas e mínimas.

As fêmeas foram alojadas na maternidade aos 105 dias de gestação, onde permaneceram até o desmame. Neste período, receberam ração de lactação farelada à base de milho e farelo de soja, com $4.725 \mathrm{kcal}$ de energia bruta, $19,79 \%$ de proteína bruta, $5,5 \%$ de extrato etéreo e 5,79\% de cinzas, fornecida de acordo com a condição corporal até o parto e, em seguida, de forma gradual, iniciando com $2 \mathrm{~kg}$ no dia do parto e acrescentando $0,5 \mathrm{~kg} /$ dia/matriz até consumo ad libitum, fracionado em tratos ofertados nos horários das 7, 14 e 21h. Para estimular o consumo dos animais, a ração fornecida, durante o período diurno, era umedecida com água na proporção de $1 \mathrm{~kg}$ de ração para $2 \mathrm{~L}$ de água. A água de bebida foi fornecida à vontade durante o período experimental.

Nas primeiras $48 \mathrm{~h}$ pós-parto as leitegadas foram equalizadas em 10 ou 11 leitões, receberam $200 \mathrm{mg}$ de ferro injetável e tiveram 2/3 da cauda cortada. Durante os primeiros sete dias de vida, os leitões tiveram acesso à fonte de aquecimento no escamoteador, através do uso de lâmpadas incandescentes de $100 \mathrm{~W}$ por $24 \mathrm{~h}$; após este período, o sistema foi acionado de 18 às $5 \mathrm{~h}$ do dia subseqüente.
As observações foram realizadas no $17^{\circ}$ dia de lactação $\left(16^{\circ}\right.$ a $\left.19^{\circ}\right)$ com auxilio de uma câmera de filmagem com adaptor universal AC - DC model:500, posicionada na parte ventral das gaiolas de maternidade, conectada a um aparelho de TV (mod. no: CN-3338 V) e um vídeo cassete recorder (VR 756/78). As imagens obtidas em 24 horas ininterruptas foram armazenadas em fitas de vídeo $\mathrm{VHS}^{\circledR}$ ajustadas em Rec. Time EP, com 360min de duração (6h), sendo avaliadas em quatro períodos do dia. No dia da filmagem não foi realizada nenhuma atividade com os animais, exceto o manejo rotineiro da criação.

Foram detectadas a freqüência (n⿳o $)$ e a duração (min) em que as matrizes ficavam sentadas (SE), em decúbito lateral (DL), decúbito ventral (DV), em pé em ócio (OEP) ou em pé, em atividade no comedouro ou bebedouro (PACB), conforme as características apresentadas na Tabela 1. As atividades correspondentes ao comportamento de eliminação (urina e fezes) foram registradas no momento em que ocorriam, sendo avaliado, apenas, o número de ocorrências nos períodos.

TABELA 1: Definição das variáveis referentes à postura das matrizes.

\begin{tabular}{l|l}
\hline \multicolumn{1}{c|}{ Variáveis } & \multicolumn{1}{c}{ Definição } \\
\hline Sentada (SE) & $\begin{array}{l}\text { Atividade em que a fêmea manteve o } \\
\text { peso corporal no posterior com o tronco } \\
\text { em contacto e amparado pelo piso. }\end{array}$ \\
\hline $\begin{array}{l}\text { Decúbito lateral } \\
\text { (DL) }\end{array}$ & $\begin{array}{l}\text { Atividade em que o a fêmea permane- } \\
\text { ceu deitada em posição lateral e com os } \\
\text { membros estendidos. }\end{array}$ \\
\hline $\begin{array}{l}\text { Decúbito ventral } \\
\text { (DV) }\end{array}$ & $\begin{array}{l}\text { Atividade em que a fêmea permaneceu } \\
\text { deitada em posição sobre o ventre, espe- } \\
\text { cialmente sobre o aparelho mamário. }\end{array}$ \\
\hline $\begin{array}{l}\text { Ócio em pé } \\
\text { (OEP) }\end{array}$ & $\begin{array}{l}\text { Atividade em que a fêmea permaneceu } \\
\text { em pé, sem nenhuma atividade aparente. }\end{array}$ \\
\hline $\begin{array}{l}\text { Em pé em ativi- } \\
\text { dade no come- } \\
\text { douro ou bebe- } \\
\text { douro (PACB) }\end{array}$ & $\begin{array}{l}\text { Atividade em que a fêmea permaneceu } \\
\text { em posição ereta e com atividade no co- } \\
\text { medouro ou bebedouro }\end{array}$ \\
\hline
\end{tabular}

A análise do comportamento lactacional foi baseada em metodologias adaptadas de Valros (2003), sendo registrada a freqüência, o tipo e a duração da amamentação (s) (Tabela 2). 
TABELA 2: Definição das variáveis comportamentais (adaptadas de Valros, 2003).

\begin{tabular}{l|l}
\multicolumn{1}{c|}{ Variáveis } & \multicolumn{1}{c}{ Definição } \\
\hline $\begin{array}{l}\text { Amamentação } \\
\text { terminada pela porca } \\
\text { (ATPOR) }\end{array}$ & $\begin{array}{l}\text { Quando elas rolavam mudando de } \\
\text { lado sobre o ventre ou baixando, } \\
\text { mas, prevenindo ou não, a massa- } \\
\text { gem pelos leitões. }\end{array}$ \\
\hline $\begin{array}{l}\text { Amamentação ter- } \\
\text { minada pelos leitões } \\
\text { (ATLEI) }\end{array}$ & $\begin{array}{l}\text { Quando eles se moviam para dis- } \\
\text { tante ou permaneciam menos ativos } \\
\text { nas glândulas mamárias }\end{array}$ \\
\hline Com sucesso (ACS) & $\begin{array}{l}\text { Quando os leitões succionavam in- } \\
\text { tensamente as tetas (cerca de 15s) } \\
\text { sem difundirem a massagem da teta } \\
\text { ou se movimentarem. }\end{array}$ \\
\hline
\end{tabular}

A amamentação foi considerada iniciada quando mais da metade da leitegada manipulou, ativamente, as tetas das matrizes, permanecendo em atividade por 60 s, e, finalizada, quando mais da metade da leitegada abandonou as tetas ou permaneceu próxima das mesmas, porém inativa. Para fins de análises foram consideradas, apenas, aquelas amamentações que excederam $60 \mathrm{~s} \mathrm{de}$ duração.

Os dados referentes à postura e ao comportamento durante a amamentação foram submetidos à análise de variância através de um delineamento inteiramente casualizado, com arranjo fatorial $4 \times 4$, ou seja, quatro ordens de parto e quatro períodos do dia. As variáveis referentes ao número em cada postura (SE, DL, DV, $\mathrm{PACB}, \mathrm{OEP}$ ) e a duração de DL, assim como, o número de cada amamentação (ATPOR, ATLEI, ACS, ASS) e a ocorrência de atividade de urinar e defecar, foram previamente transformadas em $\sqrt{(X+1)}$ para fins de análise estatística. A comparação das médias dos tratamentos foi realizada através do teste de Tukey, em nível de $5 \%$ de probabilidade, através do programa Statistical Analysis System (SAS INSTITUTE, 1997).

\section{Resultados}

Durante o período experimental prevaleceram altas temperaturas ambientais, sendo obtidos valores diários de $30,98^{\circ} \mathrm{C}$ e $24,86^{\circ} \mathrm{C}$, para as temperaturas máximas e mínimas, respectivamente. Ao contrário da umidade relativa do ar, foi detectado aumento progressivo dos valores de temperatura ambiente e do globo, assim como do ITGU, em função das horas do dia, com maiores índices ocorrendo de 12 às 14 h (Tabela 3 ).

TABELA 3: Valores médios da temperatura ambiente (Ta), temperatura do globo (Tg), umidade relativa do ar (UR) e índice de temperatura de globo e umidade (ITGU) em função da hora do dia, verificados durante o período experimental.

\begin{tabular}{c|c|c|c|c}
\hline \multirow{2}{*}{$\begin{array}{c}\text { Hora do } \\
\text { dia }\end{array}$} & \multicolumn{4}{|c}{ Variáveis climáticas } \\
\cline { 2 - 5 } & Ta $\left({ }^{\mathbf{0}} \mathbf{C}\right)$ & $\mathbf{T g}\left({ }^{\mathbf{}} \mathbf{C}\right)$ & UR $(\%)$ & ITGU \\
\hline 08 & 26,02 & 27,50 & 87,50 & 77,12 \\
\hline 10 & 28,11 & 29,60 & 78,45 & 79,24 \\
\hline 12 & 29,82 & 31,45 & 69,61 & 81,06 \\
\hline 14 & 30,27 & 31,11 & 66,50 & 80,54 \\
\hline 16 & 29,25 & 29,30 & 71,20 & 78,86 \\
\hline 18 & 27,69 & 27,17 & 77,46 & 76,66 \\
\hline Média & 28,53 & 29,35 & 75,12 & 78,91 \\
\hline
\end{tabular}

Para as variáveis referentes à freqüência (Tabela 4) e a duração (Tabela 5) em cada postura adotada pelas matrizes suínas, não houve interação $(p>0,05)$ entre os fatores ordem do parto e período do dia, sendo os valores analisados, portanto, isoladamente. O número de vezes/ dia para cada postura não diferiu significativamente $(\mathrm{p}>0,05)$ entre as ordens do parto, exceto, para a postura em decúbito lateral (DL) que foi maior $(\mathrm{p}<0,05)$ para as matrizes da segunda ordem $(11,06)$ em relação às fêmeas de quatro ou mais partos $(7,26)$, conforme Tabela 4 .

Com exceção das mensurações realizadas para atividade, na qual os animais permaneceram em ócio $(\mathrm{OEP})$, houve efeito $(\mathrm{p}<0,05)$ do período do dia para a freqüência das demais posturas comportamentais (Tabela 4).

Com relação à duração em cada postura, verificouse que as matrizes de terceiro parto despenderam mais tempo, durante 24 horas, em atividade no comedouro ou bebedouro $(\mathrm{p}<0,05)$ do que as matrizes de segundo parto (Tabela 5). Para o tempo (min) em cada posição sentada (SE), decúbito lateral (DL), decúbito ventral (DV) e em pé em ócio (OEP), o fator ordem do parto não foi determinante para ocorrência de diferenças significativas (Tabela 5). Em contraste, houve efeito significativo $(\mathrm{p}<0,05)$ do período do dia para o tempo despendido em cada postura, exceto para atividade na qual os animais permaneceram em ócio (Tabela 5). 
TABELA 4: Valores médios das variáveis referentes ao número de cada postura das matrizes suínas em lactação, mantidas sob condições de temperatura ambiente elevada, em função da ordem de parto e do período do dia.

\begin{tabular}{|c|c|c|c|c|c|}
\hline \multirow[b]{2}{*}{ Fatores } & \multicolumn{5}{|c|}{ Postura da matriz $\left(\mathrm{n}^{0}\right)$} \\
\hline & Sentada & Decúbito lateral & $\begin{array}{c}\text { Decúbito } \\
\text { ventral }\end{array}$ & Em pé em ócio & $\begin{array}{l}\text { Em pé em atividade no } \\
\text { comedouro ou bebedouro }\end{array}$ \\
\hline \multicolumn{6}{|c|}{ Ordem de parto } \\
\hline $1^{\mathrm{a}}$ & $7,50^{\mathrm{a}}$ & $9,37^{\mathrm{ab}}$ & $12,75^{\mathrm{a}}$ & $0,96^{\mathrm{a}}$ & $6,79^{a}$ \\
\hline $2^{\mathrm{a}}$ & $7,25^{\mathrm{a}}$ & $11,06^{\mathrm{a}}$ & $10,50^{\mathrm{a}}$ & $1,13^{\mathrm{a}}$ & $5,69^{\mathrm{a}}$ \\
\hline $3^{\mathrm{a}}$ & $9,89^{\mathrm{a}}$ & $9,78^{\mathrm{ab}}$ & $11,37^{\mathrm{a}}$ & $0,74^{\mathrm{a}}$ & $6,59^{\mathrm{a}}$ \\
\hline$\geq 4^{\mathrm{a}}$ & $6,78^{a}$ & $7,26^{\mathrm{b}}$ & $9,61^{\mathrm{a}}$ & $1,74^{\mathrm{a}}$ & $6,30^{\mathrm{a}}$ \\
\hline \multicolumn{6}{|c|}{ Período do dia (h) } \\
\hline 06 e 12 & $8,78^{\mathrm{ab}}$ & $9,52^{\mathrm{ab}}$ & $13,74^{\mathrm{a}}$ & $1,52^{\mathrm{a}}$ & $8,30^{\mathrm{a}}$ \\
\hline 12 e 18 & $11,04^{\mathrm{a}}$ & $11,00^{\mathrm{a}}$ & $13,04^{\mathrm{a}}$ & $1,61^{\mathrm{a}}$ & $8,56^{\mathrm{a}}$ \\
\hline 18 e 24 & $5,48^{\mathrm{c}}$ & $8,87^{\mathrm{ab}}$ & $7,61^{b}$ & $0,78^{\mathrm{a}}$ & $4,52^{b}$ \\
\hline 24 e 06 & $6,52^{\mathrm{bc}}$ & $7,48^{b}$ & $10,05^{\mathrm{ab}}$ & $0,52^{\mathrm{a}}$ & $4,05^{b}$ \\
\hline CV (\%) & 25,03 & 19,46 & 27,15 & 35,36 & 17,90 \\
\hline
\end{tabular}

Médias seguidas da mesma letra, nas colunas, não diferem significativamente entre si pelo teste de Tukey, em nível de 5\% de probabilidade.

As fêmeas ficaram sentadas por um tempo mais longo (28,26min) no $2^{\circ}$ período, quando comparado com os $10,57 \mathrm{~min}$ e os $12,43 \mathrm{~min}$ observados nos intervalos entre 24 e 6 h e 18 a $24 \mathrm{~h}$ do dia $(\mathrm{p}<0,05)$, respectivamente. Ao contrário, nos períodos considerados mais frios do dia (3 e 4), as matrizes mantiveram-se mais tempo em decúbito lateral $(\mathrm{p}<0,05)$ e mudaram menos esta postura $(\mathrm{p}<0,05)$ (Tabela 5).

A freqüência e a duração em cada tipo de amamentação não sofreram efeito significativo $(p>0,05)$ da ordem do parto (Tabela 6).
Houve efeito $(\mathrm{p}<0,05)$ do período do dia para o número de amamentações terminadas pelos leitões (Tabela 7), que se apresentaram menores $(\mathrm{p}<0,05)$ nos períodos $1(6,48)$ e $2(6,70)$ em comparação aos períodos $3(7,95)$ e $4(7,67)$. Foram também observadas diferenças $(p<0,05)$ para a freqüência de amamentações com sucesso, sendo superior no período 1, em relação aos outros horários do dia, sem efeito deste fator para as demais variáveis avaliadas.

TABELA 5: Valores médios das variáveis referentes à duração de cada postura das matrizes suínas em lactação, mantidas sob condições de temperatura ambiente elevada, em função da ordem de parto e do período do dia.

\begin{tabular}{|c|c|c|c|c|c|}
\hline \multirow[b]{2}{*}{ Fatores } & \multicolumn{5}{|c|}{ Postura da matriz (min) } \\
\hline & Sentada & $\begin{array}{c}\text { Decúbito } \\
\text { lateral }\end{array}$ & $\begin{array}{c}\text { Decúbito } \\
\text { ventral }\end{array}$ & $\begin{array}{c}\text { Em pé em } \\
\text { ócio }\end{array}$ & $\begin{array}{l}\text { Em pé em atividade no come- } \\
\text { douro ou bebedouro }\end{array}$ \\
\hline \multicolumn{6}{|c|}{ Ordem de parto } \\
\hline $1^{\mathrm{a}}$ & $15,21^{\mathrm{a}}$ & $239,63^{\mathrm{a}}$ & $70,46^{\mathrm{a}}$ & $1,83^{\mathrm{a}}$ & $32,92^{\mathrm{ab}}$ \\
\hline $2^{a}$ & $20,00^{\mathrm{a}}$ & $249,94^{\mathrm{a}}$ & $58,69^{\mathrm{a}}$ & $1,81^{\mathrm{a}}$ & $29,56^{\mathrm{b}}$ \\
\hline $3^{\mathrm{a}}$ & $19,04^{\mathrm{a}}$ & $232,44^{\mathrm{a}}$ & $64,00^{\mathrm{a}}$ & $1,63^{\mathrm{a}}$ & $42,89^{\mathrm{a}}$ \\
\hline$\geq 4^{\mathrm{a}}$ & $19,70^{\mathrm{a}}$ & $235,13^{\mathrm{a}}$ & $66,43^{\mathrm{a}}$ & $2,91^{\mathrm{a}}$ & $35,83^{\mathrm{ab}}$ \\
\hline \multicolumn{6}{|c|}{ Período do dia (h) } \\
\hline 06 e 12 & $21,48^{\mathrm{ab}}$ & $190,17^{\mathrm{b}}$ & $91,30^{\mathrm{a}}$ & $3,00^{\mathrm{a}}$ & $54,04^{\mathrm{a}}$ \\
\hline 12 e 18 & $28,26^{\mathrm{a}}$ & $207,74^{\mathrm{b}}$ & $70,91^{\mathrm{a}}$ & $2,74^{\mathrm{a}}$ & $50,39^{\mathrm{a}}$ \\
\hline 18 e 24 & $12,43^{\mathrm{b}}$ & $285,70^{\mathrm{a}}$ & $35,17^{\mathrm{b}}$ & $1,48^{\mathrm{a}}$ & $25,22^{\mathrm{b}}$ \\
\hline 24 e 06 & $10,57^{\mathrm{b}}$ & $271,95^{\mathrm{a}}$ & $64,10^{\mathrm{a}}$ & $0,86^{\mathrm{a}}$ & $12,52^{\mathrm{c}}$ \\
\hline CV(\%) & 56,84 & 22,20 & 62,56 & 35,36 & 44,44 \\
\hline
\end{tabular}

Médias seguidas da mesma letra, nas colunas, não diferem significativamente entre si pelo teste de Tukey, em nível de 5\% de probabilidade. 
TABELA 6: Comportamento da amamentação de matrizes suínas mantidas sob condições de temperatura ambiente elevada, em função da ordem do parto.

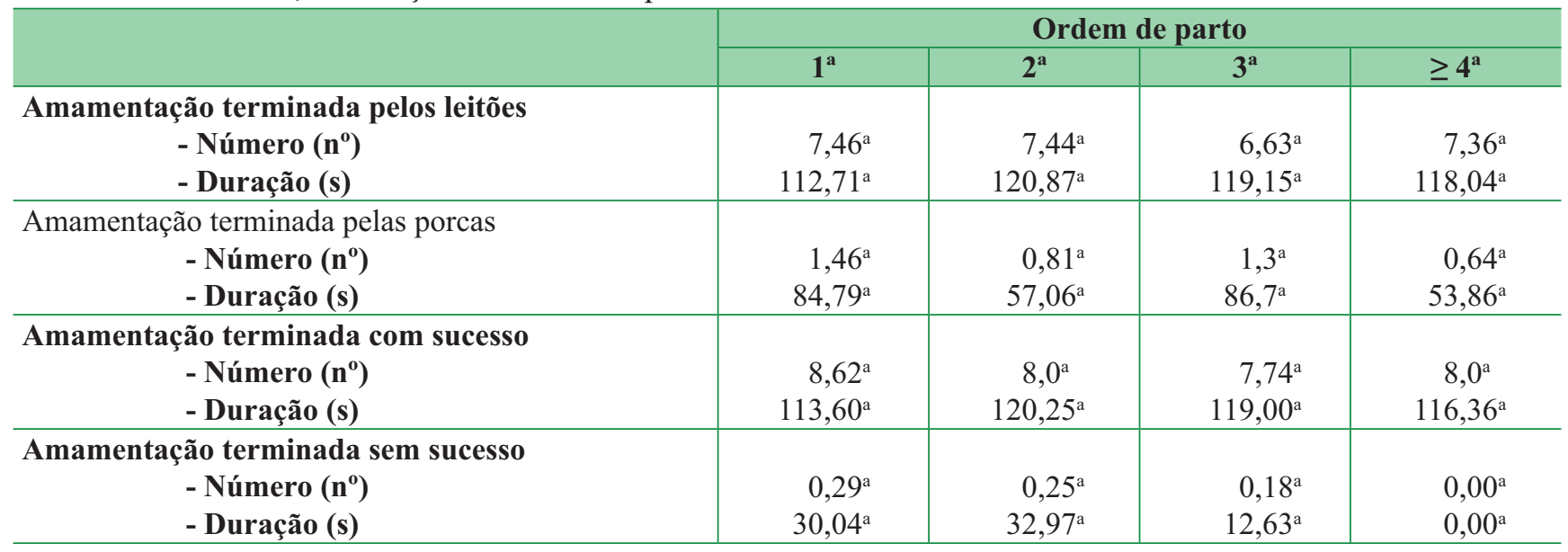

Médias seguidas da mesma letra, nas colunas, não diferem significativamente entre si pelo teste de Tukey, em nível de 5\% de probabilidade.

TABELA 7: Comportamento da amamentação de matrizes suínas mantidas sob condições de temperatura ambiente elevada, em função do período do dia.

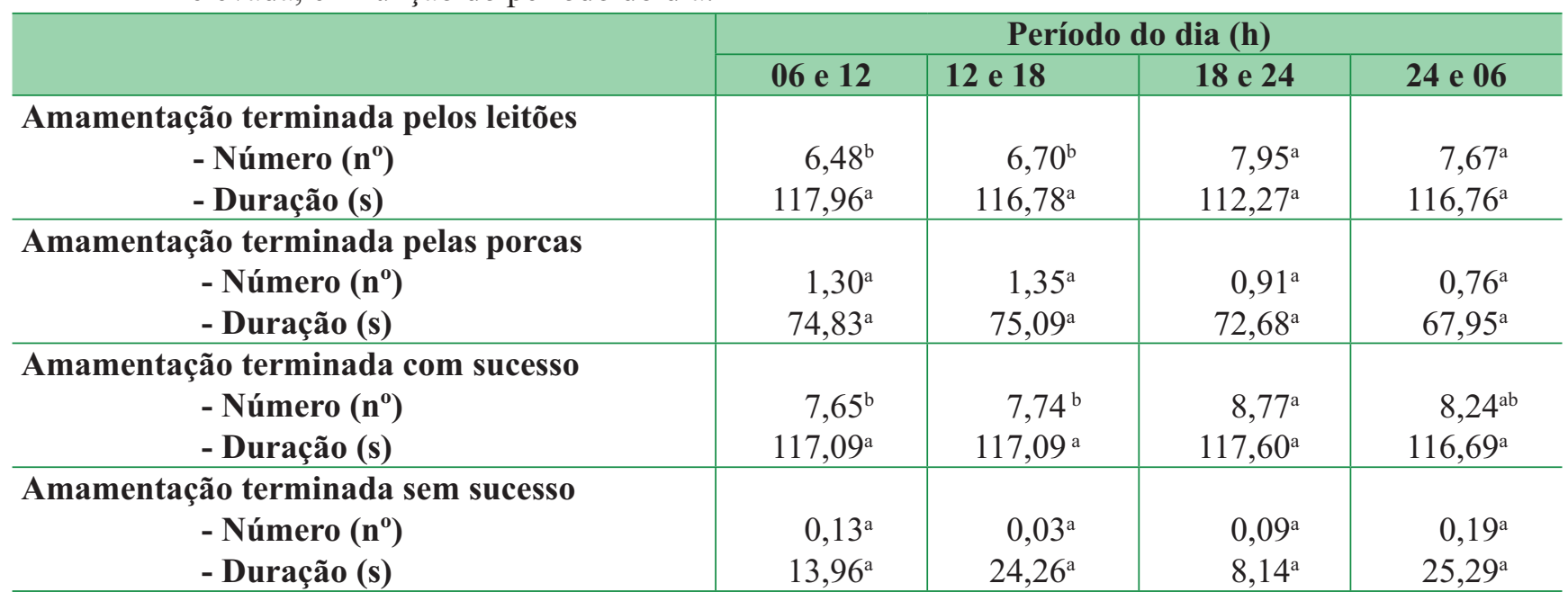

Médias seguidas da mesma letra, nas colunas, não diferem significativamente entre si pelo teste de Tukey, em nível de 5\% de probabilidade

Os registros referentes ao comportamento de eliminação (urina e fezes) das fêmeas demonstraram efeito, apenas, da ordem de parto para o ato de urinar, tendo as matrizes de segundo parto uma maior $(p<0,05)$ freqüência desta atividade durante $24 \mathrm{~h}$ do dia. Por sua vez, houve efeito do período do dia para a eliminação de fezes, sendo menor $(p<0,05)$ no período entre 6 e $12 \mathrm{~h}$ em relação aos demais períodos avaliados (Tabela 8).

\section{Discussão}

Analisando-se as variáveis ambientais, em função da hora do dia, mesmo considerando os horários de $8 \mathrm{e}$ $18 \mathrm{~h}$, quando foram registrados os menores valores para a temperatura ambiente e de globo, e ITGU, pode-se inferir que o ambiente térmico no interior da sala de maternidade estava inadequado em todos os períodos do dia, uma vez que a temperatura ambiente ultrapassou os 18 a $20^{\circ} \mathrm{C}$ e o ITGU o valor de 72 , sugerido por Black et al. (1999) para manutenção do conforto térmico de matrizes suínas em lactação. 
TABELA 8: Valores médios das variáveis referentes à freqüência de atividades de urinar e defecar das matrizes suínas híbridas, em lactação, mantidas sob condições de temperatura ambiente elevada, em função da ordem do parto e do período do dia.

\begin{tabular}{c|c|c}
\multirow{2}{*}{ Fatores } & \multicolumn{2}{|c}{ Comportamento de eliminação } \\
\cline { 2 - 3 } Orinando & \begin{tabular}{c} 
Defecando \\
\hline Ordem do parto
\end{tabular} & \\
\hline $\mathbf{1}^{\text {a }}$ & $1,63^{\mathrm{b}}$ & $0,87^{\mathrm{a}}$ \\
\hline $\mathbf{2}^{\mathrm{a}}$ & $2,44^{\mathrm{a}}$ & $1,25^{\mathrm{a}}$ \\
\hline $\mathbf{3}^{\mathrm{a}}$ & $1,37^{\mathrm{b}}$ & $0,93^{\mathrm{a}}$ \\
\hline $\mathbf{\geq 4}^{\mathrm{a}}$ & $1,52^{\mathrm{b}}$ & $0,91^{\mathrm{a}}$ \\
\hline Períodos do dia, h & & \\
\hline $\mathbf{0 6}$ e 12 & $1,87^{\mathrm{a}}$ & $1,56^{\mathrm{a}}$ \\
\hline $\mathbf{1 2}$ e 18 & $1,74^{\mathrm{a}}$ & $0,87^{\mathrm{b}}$ \\
\hline $\mathbf{1 8}$ e 24 & $1,65^{\mathrm{a}}$ & $0,74^{\mathrm{b}}$ \\
\hline $\mathbf{2 4}$ e 06 & $1,38^{\mathrm{a}}$ & $0,67^{\mathrm{b}}$ \\
\hline CV (\%) & 17,99 & 19,08 \\
\hline
\end{tabular}

Médias seguidas da mesma letra, nas colunas, não diferem significativamente entre si pelo teste de Tukey, em nível de 5\% de probabilidade.

Nestas condições experimentais, as matrizes de 3o- parto despenderam mais tempo em atividade no comedouro ou bebedouro em relação às fêmeas de $2^{\circ}$ parto, o que pode ser justificado pela maior necessidade fisiológica em atender as exigências metabólicas, e a maior produção de leite neste estádio reprodutivo.

Em geral, a freqüência (nº) e a duração (min) em cada postura adotada pelas matrizes foi modificada de acordo com o período do dia. Os animais procuraram o comedouro ou bebedouro mais vezes e permaneceram mais tempo em atividade de comer ou beber nos períodos correspondentes entre 6 e 18 h. Estas observações são fundamentadas em conceitos anteriores, de que as porcas apresentam dois picos de consumo diários, um pela manhã $( \pm 10 \mathrm{~h})$ e outro no início da noite $( \pm 17 \mathrm{~h})$, seguidos de atividades basais (Quiniou et al., 2000b). Quanto ao tempo médio de 52,2min, em que os animais permaneceram em atividade no comedouro ou bebedouro, durante o dia, e $18,87 \mathrm{~min}$, durante a noite, estes foram maiores do que o tempo de $28,8 \mathrm{~min}$ para o consumo diurno e 3,1 min para o consumo noturno, registrados por Quiniou et al. (2000b) para matrizes suínas mantidas sob estresse calórico em câmaras climáticas. Em ambiente natural, Renaudeau et al. $(2003 \mathrm{a}, \mathrm{c})$ relataram que na estação quente $\left(27,5^{\circ} \mathrm{C}\right)$ as matrizes reduzem o tamanho da refeição e o tempo de ingestão de alimentos e concentram suas atividades de procura por alimentos nos horários mais frios do dia, principalmente, no início da manhã. Entretanto, aumentam o consumo de água, justificando a permanência em pé em condições de estresse térmico.

Observou-se que entre 18 e $6 \mathrm{~h}$ as fêmeas permaneceram 79 e $75 \%$ do tempo em decúbito lateral, contrastando com os 52 e $57 \%$ verificados nos períodos subseqüentes. Como esta postura está diretamente relacionada com o ato de amamentação e produção de leite, é possível que a diminuição do tempo nela despendido e o aumento concomitante nas posições de decúbito ventral e sentadas, reduzam a massagem das tetas pelos leitões, interferindo na produção de leite nos períodos mais quentes do dia. Entretanto, de acordo com Gourdine et al. (2006), independente do efeito sazonal, as fêmeas suínas reduzem o tempo que permanecem em pé ou sentada durante a noite.

Os resultados revelaram uma postura mais reativa das matrizes nos horários mais quentes do dia (entre $6 \mathrm{e}$ $18 \mathrm{~h}$ ), sugerindo um quadro de desconforto térmico, e/ou uma resposta ao manejo (limpeza, fornecimento de ração e maior fluxo de pessoas na sala) adotado neste horário. Ressalta-se que uma maior freqüência na mudança de posição entre deitada e em pé e vice-versa, pode ser considerada como um fator de risco para a ocorrência de mortalidade por esmagamento, durante o dia, e, portanto, deve ser uma preocupação quando os animais forem submetidos a um ambiente na maternidade, onde prevaleça uma temperatura elevada.

O comportamento da amamentação (amamentação terminada pelas porcas ou pelos leitões, amamentação com ou sem sucesso) não foi modificado entre as ordens do parto, no entanto, as matrizes foram mantidas em grupos na mesma sala e, como existe "sincronização" das amamentações (Johnson et al., 2001), presume-se que esta pode ser uma explicação para a não ocorrência deste efeito.

Por sua vez, foi observado uma redução no número de amamentações terminadas pelos leitões e com sucesso nos intervalos de 6 até $18 \mathrm{~h}$ do dia, o 
que correspondeu ao período diurno, e, portanto, com temperaturas ambientais mais elevadas. Em contraste, em ambientes termoneutros, Spinka et al. (2000) não observaram efeito do horário do dia para o intervalo entre amamentações, sugerindo que as matrizes mantiveram um padrão constante de aleitamento entre os períodos, mas, a porcentagem de amamentações terminadas pela porca foi menor e a massagem pós-ejeção foi mais longa à noite, comparada ao período diurno.

Considerando todos os períodos avaliados, o intervalo médio entre as amamentações foi de $43,5 \mathrm{~min} /$ dia, portanto, semelhante (Quiniou e Noblet, 1999; Renaudeau e Noblet, 2001) ou inferior (Pajor et al., 2002; Valros, 2003) aos valores encontrados para matrizes em ambientes termoneutros; e superior aos intervalos de 26min (Quiniou e Noblet, 1999) e 37min (Renaudeau e Noblet, 2001) verificados para matrizes sob estresse calórico $\left(29^{\circ} \mathrm{C}\right)$. Entretanto, como a intensidade e a freqüência das amamentações estão relacionadas com a regulação do desenvolvimento mamário e com a produção de leite, o que se reflete no potencial de crescimento dos leitões, estratégias de manejo devem ser usadas para reduzir este intervalo (Audist et al., 2000). Neste sentido, pelo fato de ter ocorrido uma diminuição no número de amamentações com sucesso, entre 6 e 18h, presume-se que reduzindo o estresse pelo calor nestes horários, os intervalos entre as amamentações seriam neste caso reduzidos de $47 \mathrm{~min}$ (6 e 12h) para $42 \mathrm{~min}$ (12 e 18h), sendo uma recomendação importante para criadores de suínos em ambientes quentes.

Os resultados referentes ao comportamento de eliminação são difíceis de serem interpretados, pois não foi possível fazer a medição diária do consumo de água. Mas, a observação de não haver diferenças no consumo de água ( $1 /$ dia) entre matrizes submetidas a $29^{\circ} \mathrm{C}$ ou em temperaturas ambientais de $25^{\circ} \mathrm{C}$ (Quiniou et al., 2000a) e até a $18^{\circ} \mathrm{C}$ (Quiniou et al., 2000b), talvez possa justificar a ausência de efeito do período do dia para esta variável fisiológica, além do mais, uma maior freqüência de eliminação de fezes no período entre $6 \mathrm{e}$ $12 \mathrm{~h}$, concomitante com a maior procura e tempo usado pelo animal no comedouro ou bebedouro, e com o maior consumo alimentar na refeição matinal (dados não publicados), são indicadores bastante expressivos que a variação da temperatura ambiente não foi suficiente para alterar significativamente o comportamento de eliminação de urina nos períodos avaliados.

Em síntese, matrizes suínas lactantes mantidas em ambiente quente são mais reativas nos períodos mais quentes do dia e reduzem a freqüência da postura em decúbito lateral e o número de amamentações terminadas pelos leitões, com o mesmo padrão de conduta materna, independente da ordem de parto, para a maioria das variáveis pesquisadas.

\section{Agradecimentos}

À empresa Granjita S/A do Sr. J. Nunes de Oliveira Filho, por ter financiado este Projeto, e em especial a Dra. Najda Souza e sua equipe de trabalho, por ter viabilizado esta pesquisa.

\section{Referências}

Algers, B. 1993. Nursing in pigs: communicating needs and distributing resources. Journal of Animal Science, 71 (10): 2826-2831.

Audist, D. E.; Carlson, D.; Morrish, L.; Wakeford, C. M.; King, R. H. 2000. The influence of suckling interval on milk production of sows. Journal of Animal Science, 78 (8): 2026-2031.

Black, J. L.; Bray, H. J.; Giley, L. R. 1999. The thermal and infection environment. In: Kyriazakis, I. (ed.). A quantitative biology of the pigs. Disponivel em <http://www. cabi-publishing.org>. Acesso em 10 de dezembro de 2007.

Buffington, D. E.; Colazzo-Arocho, A.; Canton, C. H.; Pitt, D. 1981. Black globe-humidity index (BGHI) as comfort equation for dairy cows. Transaction of the ASAE, 24: 711-714.

Fundação de Desenvolvimento Municipal do Interior de Pernambuco (Recife, PE). 1994. Histórico do município de Paudalho. In: Fundação de Desenvolvimento Municipal do Interior de Pernambuco (ed.). Perfil municipal do interior de Pernambuco. Fundação de Desenvolvimento Municipal do Interior de Pernambuco, Recife, Brasil, p.639-642.

Gourdine, J. L.; Bidanel, J. P.; Noblet, J.; Renaudeau, D. 2006. Effects of season and breed on the feeding behavior of multiparous lactating sows in a tropical humid climate. Journal of Animal Science, 84 (1): 469-480.

Johnson, A. K.; Morrow-Tesch, J. L.; McGlone, J. J. 2001. Behaviour and performance of lactating sows and piglets reared indoor and outdoors. Journal of Animal Science, 79 (12): 2571-2579.

Pajor, E. A.; Weary, D. M.; Caceres, C.; Fraser, D.; Kramer, D. L. 2002. Alternative housing for sows and litters Part 3. Effects of piglet diet quality and sow-controlled housing on performance and behaviour. Applied Animal Behaviour Science, 76 (4): 267-277.

Quiniou, N.; Noblet, J. 1999. Influence of high ambient tempera- 
tures on performance of multiparous lactating sows. Journal of Animal Science, 77 (8): 2124-2134.

Quiniou, N.; Renaudeau, D.; Dubois, S.; Noblet, J. 2000a. Effect of diurnally fluctuating high ambient temperatures on performance and feeding behaviour of multiparous lactating sows. Animal Science, 71 (3): 571-575.

Quiniou, N.; Renaudeau, D.; Dubois, S.; Noblet, J. 2000b. Influence of high ambient temperatures on food intake and feeding behaviour of multiparous lactating sows. Animal Science, 70 (3): 471-479.

Renaudeau, D.; Noblet, J. 2001. Effects of exposure to high ambient temperature and dietary protein level on sow milk production and performance of piglets. Journal of Animal Science, 79 (6): 1540-1548.

Renaudeau, D.; Anais, C.; Noblet, J. 2003a. Effects of dietary fiber on performance of multiparous lactating sows in tropical climate. Journal of Animal Science, 81 (3): 717-725.

Renaudeau, D.; Noblet, J.; Dourmand, J. Y. 2003b. Effect of ambient temperature on mammary gland metabolism in lactating sows. Journal of Animal Science, 81 (1): 217-231.

Renaudeau, D.; Weisbecker, J. L.; Noblet, J. 2003c. Effect of season and dietary fibre on feeding behaviour of lactating sow in tropical climate. Animal Science, 77: 429-437.
SAS INSTITUTE. 1997. User's guide: statistics. Versão 6.12. North Carolina State University, Cary, USA, CD-ROM.

Spencer, J. D.; Boyd, R. D.; Cabrera, R.; Alee, G. L. 2003. Early weaning to reduce tissue mobilization in lactating sows and milk supplementation to enhance pigs weaning weight during extreme heat stress. Journal of Animal Science, 81 (8): 2041-2052.

Spinka, M.; Illmann, G.; Jonge, F.; Andersson, M.; Schuurman, T.; Jensen, P. 2000. Dimensions of maternal behaviour characteristics in domestic and wild x domestic crossbred sows. Applied Animal Behaviour Science, 70 (2): 99-114.

Thodberg, K.; Jensen, K. H.; Herskin, M. S. 2002. Nursing behaviour, postpartum activity and reactivity in sows. Effects of farrowing environment, previous experience and temperament. Applied Animal Behaviour Science, 77 (1): 53-76.

Valros, A. 2003. Behaviour and physiology of lactating sowsassociations with piglet performance and sow postweaning reproductive success. $\mathrm{PhD}$ Thesis, Faculty of Veterinary Medicine, University of Helsinki, Finland, 79 pp. 